\title{
Drying characteristics of fish cracker under different drying techniques
}

\author{
1,*Abdullah, S., ${ }^{1}$ Musa, N., ${ }^{2}$ Rukunudin, I.H. and ${ }^{1}$ Shaari, A.R. \\ ${ }^{1}$ Department of Chemical Engineering Technology, Faculty of Engineering Technology, University \\ Malaysia Perlis, 02100 Padang Besar, Malaysia \\ ${ }^{2}$ School of Bioprocess Engineering, University Malaysia Perlis, 02600 Arau, Perlis, Malaysia
}

\begin{abstract}
Article history:
Received: 28 September 2018

Received in revised form: 8

January 2019

Accepted: 17 January 2019

Available Online: 23 January 2019
\end{abstract}

Keywords:

Fish cracker,

Drying techniques,

Mathematical modelling,

Lewis model

DOI:

https://doi.org/10.26656/fr.2017.3(4).147

\begin{abstract}
Fish cracker is a popular snack in Malaysia. In preparation of fish cracker, drying is one of the important steps. Drying is used as for the preservation of fish crackers during storage. In this study, the effects of different drying techniques on the drying kinetics of fish crackers were investigated. Fresh fish cracker samples were attained from two manufacturers in Tanjung Dawai Kedah, Malaysia which were Persatuan Nelayan Kawasan (M1) and Perusahaan Hasil Laut Musliha (M2). Samples were dried under sunlight, oven and vacuum oven. Results showed that M1 sample exhibited higher drying rate than M2 under all techniques. It is due to the difference in thickness. All of the drying kinetics fall under falling rate period except for M1 samples dried by vacuum oven. Mathematical modelling was performed to compare experimental drying kinetics with predicted data by Lewis model. Vacuum oven drying showed the best fit to the model which gave highest $\mathrm{R}^{2}$ and lowest SSE, RMSE and $\mathrm{c}^{2}$ as compared to sun-dry and oven. Therefore, data predicted by Lewis model could be used to describe the drying of fish cracker using vacuum oven.
\end{abstract}

\section{Introduction}

In Malaysia, fish cracker is one of the most popular snacks. It is prepared in both fresh and dried forms (Taewee, 2011). Fish cracker is made from fresh fish flesh, flour, water and seasoning. It is usually fried, and it expands to give puffy and crispy characteristics. The drying process is used for preservation during storage. It is an ancient food preservation technique mainly to inhibit the growth of bacteria, yeasts and mold by reducing the moisture content to a certain safe level (Santana, 2012). Currently, fish cracker is still being dried under sun drying. This technique is considered the most convenient and practical due to its low labor and operating cost. However, this technique takes a longer drying period, higher final moisture content and nonhygiene (Mohamaddan et al., 2015). Oven drying is one of the methods that is widely used due to its simplicity. For instance, oven drying of Vernonia amygdalina leaves (Alara et al., 2017) and walnut (Maorun et al., 2016). In oven method, samples are dried by heating at a relatively low temperature. Vacuum oven drying is a hybrid method which combines the benefit of oven drying under vacuum condition. This creates sufficient driving force in term of vapour pressure difference between sample moisture and the surrounding air. Taste of the food could be preserved because of the shorter time used. Since the manufacturing of the fish cracker is mostly practiced in small scale industry, the knowledge of the drying behavior is still lacking. Therefore, a scientific understanding of the drying characteristic is required to explain the effect of the drying on final product quality for safe longer storage duration. This project is performed to establish the drying characteristics under different methods of locally manufactured fish crackers for future investigation of its final product quality during storage in term of proximate composition and expansion after frying.

\section{Materials and methods}

\subsection{Fresh samples collection and preparation}

Fresh fish cracker samples of were purchased from two different manufacturers, PNK Tanjung Dawai (M1) and Perusahaan Hasil Laut Musliha (M2) at Tanjung Dawai, Kedah, Malaysia. The samples were vacuum sealed prior to store in the chest freezer for further uses.

\subsection{Dry matter weight determination}

Samples from both manufacturers were weighed $1 \mathrm{~g}$ and were prepared in three replications. Then the 
samples were dried at $105^{\circ} \mathrm{C}$ for $24 \mathrm{hrs}$. After drying, the samples dry matter weight $\left(\mathrm{w}_{\mathrm{dm}}\right)$ were determined.

\subsection{Drying experiments}

The fish crackers were cut into a dimension of $8 \mathrm{~cm}$ ' $4 \mathrm{~cm}$. Each sample from M1 and M2 were weighed in range of 6 to $9 \mathrm{~g}$ and 3 to $6 \mathrm{~g}$ respectively. Samples were prepared in three replications. Then the samples were dried under sunlight, oven $\left(60^{\circ} \mathrm{C}\right)$ and vacuum oven $\left(60^{\circ}\right.$ C). For each technique, thin layer samples were evenly distributed on perforated aluminum trays. The sun drying experiment was performed in between 9 a.m. to 4 p.m. In the meantime, the sun-dried samples were kept in airtight glass containers to sustain their moisture content in a refrigerator. The samples' weight was recorded in 1-hour interval for sun dried and the rest was 15 min. Drying process was continued until the weight change of the last three consecutive readings were less than $0.001 \mathrm{mg}$. The samples were considered to reach their equilibrium moisture content (EMC).

\subsection{Drying curve construction}

Drying curve of drying rate versus moisture content was plotted. The equilibrium moisture content was calculated using Equation 1.

$$
\mathrm{EMC}_{(\mathrm{d} . \mathrm{b})}=\frac{w_{f}-w_{\mathrm{dm}}}{w_{\mathrm{dm}}}
$$

Where $\mathrm{EMC}_{(\mathrm{d} . \mathrm{b})}$ is dry basis equilibrium moisture content; $\mathrm{w}_{\mathrm{f}}$ is the final weight of the samples $(\mathrm{g})$; and $\mathrm{w}_{\mathrm{dm}}$ is dry matter weight of the sample $(\mathrm{g})$. Then, the drying rate $(\mathrm{DR})$ was calculated using the equation below:

$$
\mathrm{DR}=\frac{\mathrm{MC}_{t+\mathrm{dt}}-\mathrm{MC}_{t}}{\mathrm{dt}}
$$

Where $\mathrm{MC}$ is moisture content and $\mathrm{t}$ is time. Drying curves of moisture content ( $\mathrm{g}$ water/ $\mathrm{g} \mathrm{dm}$ ) against drying time and drying rate $(\mathrm{g}$ water / $\mathrm{t}$ ) against moisture content was plotted at each drying method.

\subsection{Mathematical modeling of drying kinetics}

Mathematical modelling was performed using established Lewis model. Moisture ratio (MR) was determined by using the equation below:

$$
M R=\frac{M C_{t}-E M C}{M C_{i}-E M C}
$$

The experimental data were compared with predicted MR using the Lewis model equation as shown below

$$
M R=\exp (-k t)
$$

Where $\mathrm{k}$ is Lewis constant. The value of $\mathrm{k}$ was determined by the linear regression analysis. This was done by taking logarithmic both side of Equation 4 . $\ln M R=-k t+c$

After retrieving the $\mathrm{k}$ values, the predicted MR was calculated using Equation 5. Then, graphs of predicted MR against experimental MR were plotted for comparison.

\subsection{Statistical analysis}

The statistical analysis was performed for comparison between the experimental data and the predicted data. Four parameters: coefficient of determination $\left(\mathrm{R}^{2}\right)$, the sum of square error (SSE), reduced chi-square $\left(\mathrm{c}^{2}\right)$ and root mean square error (RMSE) were calculated to evaluate the best fit model. All parameters were calculated by using the following equations:

$$
\begin{aligned}
& \chi^{2}=\frac{\sum_{\mathrm{t}=1}^{\mathrm{N}}\left(\mathrm{MR}_{\text {exp }, \mathrm{i}}-\mathrm{MR}_{\text {pred }, \mathrm{i}}\right)^{2}}{\mathrm{~N}-\mathrm{n}} \\
& S S E=\frac{1}{N} \sum_{t=1}^{N}\left(M R_{\text {exp }, i}-M R_{\text {pred }, i}\right) \\
& R M S E=\sqrt{\frac{1}{\mathrm{~N}} \sum_{\mathrm{i}=1}^{\mathrm{N}}\left(\mathrm{MR}_{\text {exp }, \mathrm{i}}-\mathrm{MR}_{\text {pred }, \mathrm{i}}\right)^{2}}
\end{aligned}
$$

Where $\mathrm{MR}_{\text {exp,i }}$ the experimental moisture; $\mathrm{MR}_{\text {pre, } \mathrm{i}}$ is predicted moisture ratio; $\mathrm{N}$ and $\mathrm{n}$ are the number of observations and the number of constants respectively. The higher $\mathrm{R}^{2}$ values and the lower $\mathrm{c}^{2}$, SSE and RMSE values were considered as the best fit model.

\section{Results and discussion}

\subsection{Effect of drying techniques on drying rate and moisture content}

The effects of the drying techniques on drying rate and moisture content are shown in Figures 1 and 2 for both manufacturers. As seen from the figures when the drying rate decreased, the moisture content also decreased. It was because samples contained high free water at initial, thus creates a higher rate. Significant humidity difference between material internal structure and surrounding air forms sufficient driving force for this trend to be happened. After that, the rate of drying began to decrease as the moisture content started to reduce. Drying process completed when the samples had reached equilibrium moisture content.

As indicated in Figures 1 and 2, there was no constant rate period in the drying of fish crackers under all of the techniques, except for the M1 sample dried under vacuum oven. The drying process only took place in the falling rate period. Similar results were also reported in the drying of kiwi slices (Chin et al., 2015). During the falling rate period, the moisture movement is highly affected by the diffusion as the dominant physical mechanisms in the drying process (Elamin, 2014).

A constant rate period was found in the drying curve 
of M1 fish cracker sample dried under vacuum oven within moisture content of $0.67 \mathrm{~g} \mathrm{H}_{2} \mathrm{O} / \mathrm{g} \mathrm{DM}$ to 0.39 $\mathrm{H}_{2} \mathrm{O} / \mathrm{g} \mathrm{DM}$ as shown in Figure 1. At this stage, the rates showed insignificant difference. Drying rate is also can be defined as the rate at which moisture evaporates. It relates with gas mass-transfer coefficient and the difference between the humidity of moisture at the liquid surface and in the main surrounding air. During constant rate period, this humidity remains constant where the transfer of moisture in samples capillary and interstices to the surface exactly equal to as it evaporates there. Constant rate period is rarely found in biological materials. One was found in the drying of pumpkin slice using microwave vacuum and microwave multi-flash drying (Ricardo et al., 2018).

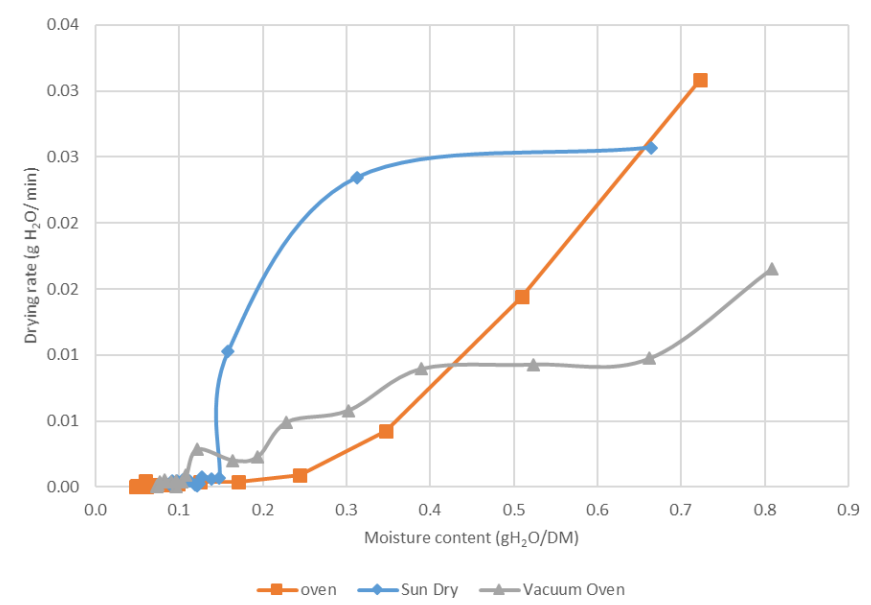

Figure 1. Variation of drying rate and moisture content of the fish crackers under different drying technique for M1

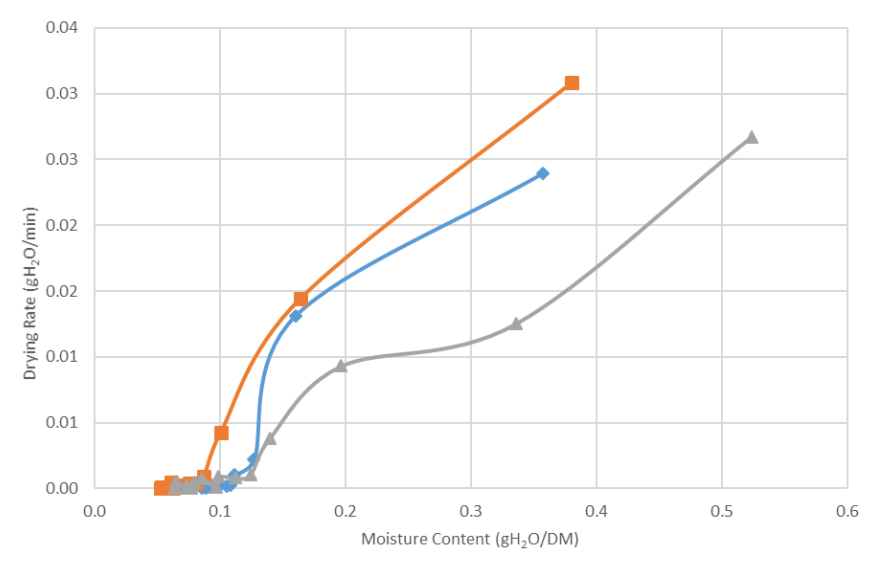

$\rightarrow$ Sun Dry $\rightarrow$-Oven $\leadsto$-Vacuum Oven

Figure 2. Variation of drying rate and moisture content of the fish crackers under different drying technique for M2

\subsection{Mathematical modelling using the Lewis model}

Experimental data gained was compared with predicted data by Lewis model. Lewis mathematical model was initially tested to fit the experimental data of the drying kinetics because of its simplicity. The assumption made for this model is that there occurs negligible internal resistance, indicative of no resistance to moisture movement from within the interior of the material out to the surface of the material (Lewis, 1921). This established mathematical model is successfully used to describe the drying behavior of avocado seed (Dhanushkodia et al., 2017) and cashew (Avhad and Marchetti, 2016).

The result of the mathematical modelling of the experiments is shown in Figures 3 and 4. From the figures, the comparison between experimental and predicted can be visualized for vacuum oven, oven and sundry techniques.

Statistical analysis was conducted to evaluate the best fit model. The results are tabulated in Table 1. It was found that vacuum oven for M1 sample fitted predicted data well as compared to the other drying techniques due to the highest $\mathrm{R}^{2}$ and the lowest SSE, RMSE and $\mathrm{c}^{2}$. Therefore, it can be concluded that Lewis is the best model that could be used to represent the vacuum drying characteristics of the fish crackers. In contrary, the comparison between experimental data and predicted data gave lower $\mathrm{R}^{2}$ and higher SSE, RMSE and $\mathrm{c}^{2}$ values for the samples from M2 under oven drying followed by sun and vacuum drying method. Thus, this model is not suitable to describe the drying behaviors of fish cracker from M2 using oven method.

\section{Conclusion}

From the results obtained, several conclusions can be made. Only drying under vacuum oven for M1 sample had experienced a constant rate period. Other drying processes fall in the falling rate period. Lewis model was found to be the best fit model to describe the drying characteristics of fish crackers under vacuum drying condition statistically. The statistical analysis gave the highest value of $\mathrm{R}^{2}$ and the lowest SSE, RMSE and $\mathrm{c}^{2}$ indicates the best fit model. Mathematical modelling needs to be performed for other established models. Data gathered from this work is beneficial for further investigation of physical characteristics and proximate composition of locally manufactured fish crackers especially to the small-medium entrepreneurs.

\section{Acknowledgment}

This research project has been supported by University Malaysia Perlis (UniMAP) under Short Term Research Grant fund (Grant no. 9006-00507) and Faculty of Engineering Technology, UniMAP.

\section{References}

Alara, OR. Abdurahman, N.H. and Olalere, O.A. (2017). Mathematical modelling and morphological properties of thin layer oven drying of Vernonia 


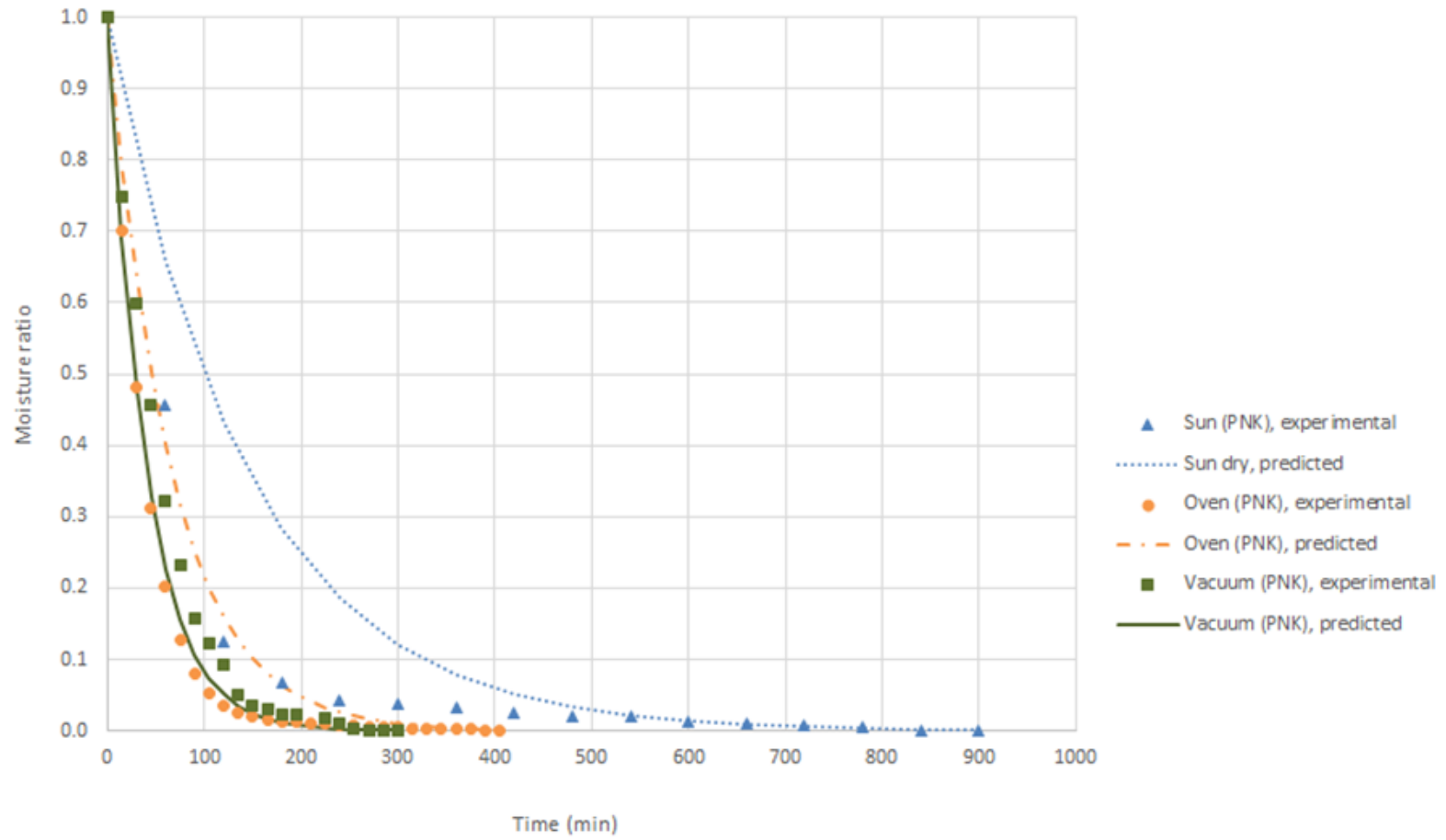

Figure 3. Comparison between experimental and predicted data by Lewis model for M1 sample

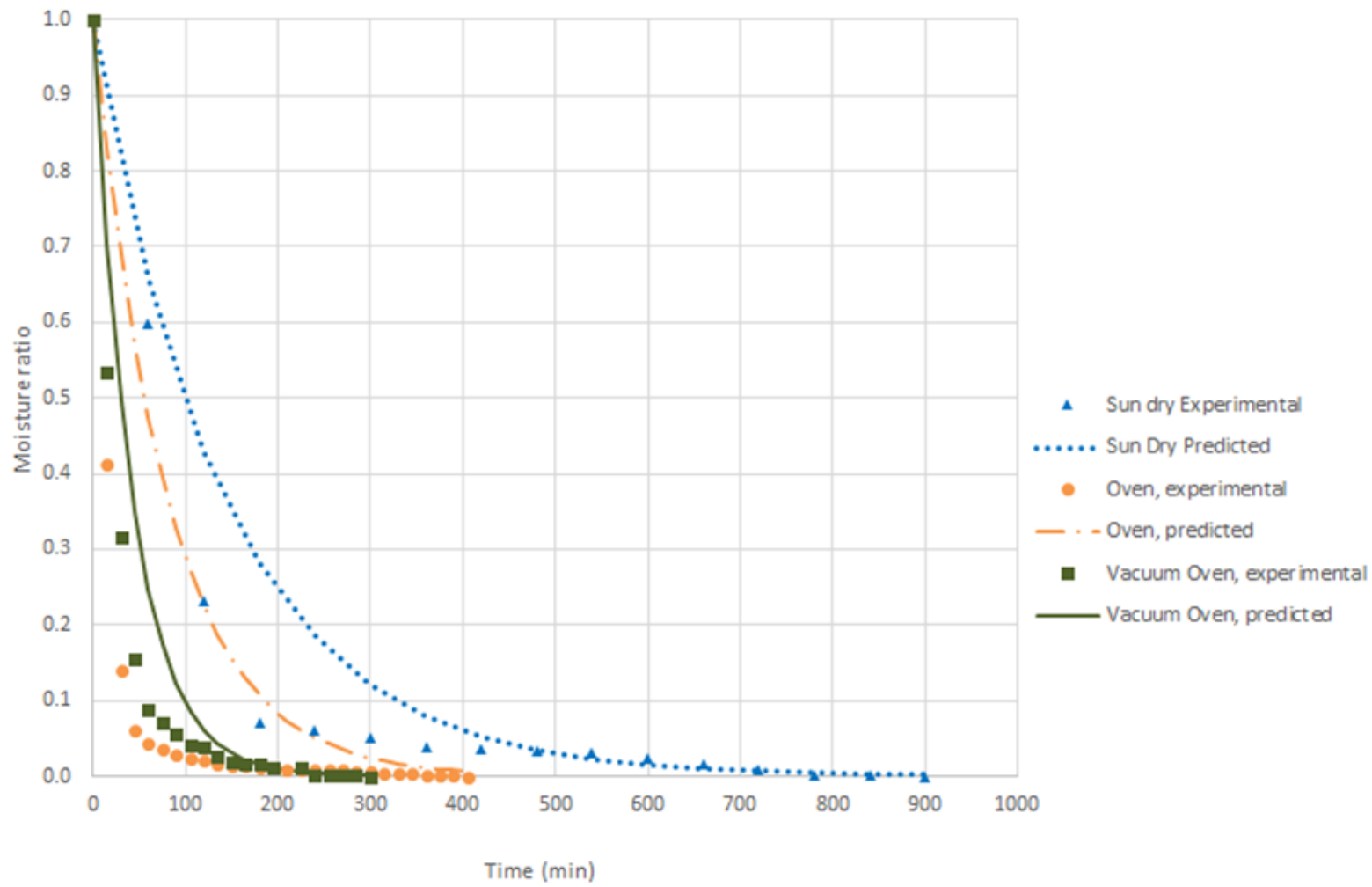

Figure 4. Comparison between experimental and predicted data by Lewis model for M2 sample

Table 1. Statistical analysis result of mathematical modelling

\begin{tabular}{ccccccc}
\hline Drying techniques & Manufacturers & Drying constant & $\mathrm{R}^{2}$ & SSE & RMSE & $\mathrm{c}^{2}$ \\
\hline \multirow{2}{*}{ Sun drying } & M1 & $\mathrm{k}=-0.4212$ & 0.9350 & 0.0440 & 0.0830 & 0.0085 \\
& $\mathrm{M} 2$ & $\mathrm{k}=-0.3708$ & 0.8515 & 0.0850 & 0.1381 & 0.0235 \\
\hline \multirow{2}{*}{ Oven drying } & M1 & $\mathrm{k}=-0.0153$ & 0.9336 & 0.0620 & 0.0920 & 0.0095 \\
& $\mathrm{M} 2$ & $\mathrm{k}=-0.0124$ & 0.6118 & 0.1410 & 0.2190 & 0.0530 \\
\hline \multirow{2}{*}{ Vacuum drying } & M1 & $\mathbf{k}=\mathbf{- 0 . 0 2 4 8}$ & $\mathbf{0 . 9 8 1 6}$ & $\mathbf{0 . 0 3 5 5}$ & $\mathbf{0 . 0 5 4 0}$ & $\mathbf{0 . 0 0 3 4}$ \\
& $\mathrm{M} 2$ & $\mathrm{k}=-0.0233$ & 0.9374 & 0.0488 & 0.0850 & 0.0084 \\
\hline
\end{tabular}


amygdalina leaves. Journal of the Saudi Society of Agricultural Science [Article in Press] https:// doi.org/10.1016/j.jssas.2017.09.003

Avhad, M.R. and Marchetti, J.M. (2016). Mathematical modelling of the drying kinetics of Hass avocado seeds. Industrial Crops and Products, 91, 76-87. https://doi.org/10.1016/j.indcrop.2016.06.035

Chin, S.K., Siew, E.S. and Soon, W.L. (2015). Drying characteristics and quality evaluation of kiwi slices under hot air natural convective drying method. International Food Research Journal, 22(6), 21882195.

Dhanushkodia, S., Vincent, H.W. and Sudhakar, K. (2017). Mathematical modeling of drying behavior of cashew in a solar biomass hybrid dryer. ResourceEfficient Technologies, 3(4), 359-364. https:// doi.org/10.1016/j.reffit.2016.12.002

Elamin, A. (2014). Experimental characterization and modeling of thin-layer drying of mango slices. International Food Research Journal, 21(5), 19111917

Lewis, W.K. (1921). The rate of drying solid materials. Industrial and Engineering Chemistry, 13(5), 427432. https://doi.org/10.1021/ie50137a021

Fu, M., Qu, Q., Yang, X. and Zhang, X. (2016). Effect of intermittent oven drying on lipid oxidation, fatty acids composition and antioxidant activities of walnut. LWT - Food Science and Technology, 65, 1126-1132. https://doi.org/10.1016/j.lwt.2015.10.002

Mohamaddan, S., Suffian, M.S.Z.M., Mohtar, A.M.A.A.M., Mohtadzar, N.A.A. and Junaidi, N. (2016). Development of Keropok Keping Drying Machine for Small and Medium Enterprises (SMEs). IOP Conference Series: Materials Science and Engineering, 114, $012037 . \quad$ https:// doi.org/10.1088/1757-899X/114/1/012037

Monteiro, R.L., Link, J.V. Tribuzi, G., Carciofi, B.A.M., Laurindo, J.B. (2018). Microwave vacuum drying and multi-flash drying of pumpkin slices. Journal of Food Engineering, 232, 1-10. https:// doi.org/10.1016/j.jfoodeng.2018.03.015

Santana, P., Huda, N. and Yang, T.A. (2012). Technology for production of surimi powder and potential of applications. International Food Research Journal, 19(4), 1313-1323.

Taewee, T.K. (2011). Cracker "Keropok": A review on factors influencing expansion. International Food Research Journal, 18(3), 855-866. 